\title{
Effect of roasting time and temperature on volatile component profiles during nib roasting of cocoa beans (Theobroma cacao)
}

\begin{abstract}
The effect of nib roasting time and temperature on volatile component profiles was studied using response surface methodology (RSM) which consisted of two independent variables: time $(5 \ddot{i} 65 \mathrm{~min})$ and temperature $\left(110 \ddot{1} 170^{\circ} \mathrm{C}\right)$. A steam distillation extraction (SDE) method was used to extract and gas chromatographï mass spectrometry equipped with an ICIS data system was used to identify the volatile compounds. Tetramethylpyrazine, trimethylpyrazine, phenethyl acetate, isoamyl acetate, 3-methylbutyl acetate, phenylacetaldehyde, benzaldehyde and 2-phenylethanol were present in all treatments. Pyrazine formation increased as roasting time and temperature were increased. The number of pyrazines increased from 4 to 11 and 25 , respectively, when roasting, time was increased from 5 to 35 and $65 \mathrm{~min}$ at $140^{\circ} \mathrm{C}$. The unit area of esters increased (up to 1700ї 1800) when the roasting time was increased from 15 to $65 \mathrm{~min}$ (at $110 \mathrm{i} 120^{\circ} \mathrm{C}$ ). However, the unit area of carbonyls linearly decreased with an increasing roasting temperature at shorter time $(5 \mathrm{i} 25 \mathrm{~min})$. The unit area of phenols was enormously reduced at the highest roasting temperature $\left(1601170^{\circ} \mathrm{C}\right)$ with longest roasting time (45ï $65 \mathrm{~min}$ ) while that of alcohol slightly decreased as roasting time and temperature were increased.
\end{abstract}

Keyword: Carbonyls; Esters; Nib; Pyrazines; Roasting; Temperature; Time 